\title{
LITERATURA E AUTORITARISMO - A CONSERVAÇÃO DA VIOLÊNCIA
}

A revista eletrônica Literatura e Autoritarismo chega ao seu número 24 discutindo a temática da violência que insiste em permanecer de forma consistente e constante - muitas vezes mascarada de ideologias que pregam a igualdade e a democracia, mas que na prática sustentam processos autoritários e de exclusão. O título da publicação procura destacar o propósito dos textos que convergem a esta edição e deixar latente os mecanismos que operam para que um estado de violência esteja sempre presente e atuante nas nossas práticas sociais. É relevante situar o posicionamento dessa edição na crítica que Walter Benjamin elabora sobre a violência presente no ensaio Para uma crítica da violência ${ }^{1}$. Nesse texto, Benjamin confronta a necessidade de assimilar um sentimento de perda sobre a cultura somado ao da aceitação de suas incongruências. Redimensionar a noção de cultura e incluir nela a ideia de barbárie não é tão somente olhar para um passado de forma diferente, mas inserir um novo leitor nesse passado que não veja a si como redentor dos vencidos ou defensor dos vencedores.

Partindo do pressuposto de que o texto literário cria um sistema social completo, Andre Rezende Benatti aborda o status de entretenimento que a violência e a crueldade atingiram no contexto histórico contemporâneo. Com o título de VIOLÊNCIA E SOCIEDADE EM FESTA NO COVIL, DE JUAN PABLO VILLALOBOS, Benatti defende que a "obra de Villalobos está longe de ser uma literatura de mero entretenimento, mergulhando profundamente em assuntos de extrema atualidade e importância para a compreensão de, pelo menos, uma parte da sociedade contemporânea."

Aulus Martins e Isadora Mattos abordam a literatura de cárcere no texto UM TESTEMUNHO DO CÁRCERE: O CASO SOBREVIVENTE ANDRÉ DU RAP (DO MASSACRE DO CARANDIRU). Amparando-se, principalmente, 
nas reflexões de Seligmann-Silva, Martins e Mattos discutem a narrativa Sobrevivente André Du Rap (do massacre do Carandiru) (2002), enfatizando que se trata de uma produção "representativa da 'nova literatura de cárcere brasileira' e considerada o primeiro relato em livro sobre o mencionado evento do Carandiru. Ela é aproximada por muitos críticos e teóricos à acepção hegemônica de testimonio latino-americano."

\section{A MÁQUINA DE JOSEPH WALSER: INDIFERENÇA E} TOTALITARISMO é o título do artigo de Maria Isabel Bordini que analisa o segundo romance de uma tetralogia denominada $O$ Reino, do escritor português contemporâneo Gonçalo M. Tavares. Sua reflexão parte da experiência da guerra, mais precisamente da presença de uma situação de conflito que perpassa os quatro romances. A indiferença em meio a guerra é o tema central do segundo livro - contrastando com o conflito armado do primeiro - cujo enredo "acompanha principalmente a perspectiva de Joseph Walser, empregado que ocupa uma colocação inferior (é um trabalhador de base) numa das fábricas de Leo Vast, o rico industrial que já aparecera no romance anterior, para quem a guerra trouxe ganhos econômicos e que, por conta disso, se decepciona com o seu fim.". O fim da guerra não culmina com o fim da violência e de um estado de vigília em prol da sua permanência, ao contrário do desejo consciente da maior parte da sociedade, evidenciando, assim, a contradição humana a partir das ações do encarregado da fábrica onde Walser trabalha que "propõe a guerra como uma ocasião de exercício de disciplina, a princípio. Mas ao final veremos que, para Klober, essa disciplina está ligada a um individualismo extremo e a um desejo de domínio total sobre os demais."

João Paulo Ayub discute, no artigo intitulado ENTRE A GRAMÁTICA E A LEI - PODER, LINGUAGEM E RESISTÊNCIA NA LITERATURA DE GRACILIANO RAMOS, a atenção que Graciliano Ramos dedicou à linguagem, enfatizando as metáforas relacionadas com a violência e com as limitações que os homens impõem a si e aos outros em seu percurso histórico e social. Dessa forma, a leitura de Ayub de parte da obra de Graciliano Ramos se volta para um "modo de ser da linguagem que opera na distribuição de invisibilidades, silenciando e transformando indivíduos não merecedores da posição de 
sujeitos em simples objetos. O ultraje da linguagem que institui a verbosidade ardilosa dos mecanismos de sujeição é como a opressão social que salta aos olhos e acomete o corpo."

O artigo de Maricélia Nunes dos Santos, intitulado REPRESENTAÇÕES DA MULATA E DO BRANCO NO CONTO "UM ESPECIALISTA", DE LIMA BARRETO, baseia-se nas concepções de Gilberto Freyre, Sérgio Buarque de Holanda e Queiroz Junior para analisar como são representadas as relações entre o homem branco e a mulher mulata no conto, evidenciando o preconceito de cor existente na organização social do Brasil, que estimula uma visão estereotipada da mulher. Por outro lado, de acordo com a articulista, o conto "procede também a uma revisão do tipo de relação que se estabelece entre brancos e afrodescendentes", de forma que "a mulata é decorrência das ações desse branco, de todo o processo de miscigenação e exclusão caracterírstico da sociedade brasileira".

Yur Maria Sperb e Eunice Piazza Gai apontam, em seu texto A PRESENÇA DE DIFERENTES GÊNEROS LITERÁRIOS EM OBRAS DE ALAN PAULS, diversos aspectos da literatura deste escritor argentino, entre os quais o hibridismo de gêneros e também a representação da "problemática pela qual passou a sociedade argentina na década de 70 , conhecida como 'Os anos de chumbo"' nos dois volumes História do pranto e História do cabelo, que juntamente com História do dinheiro compõem a trilogia da Argentina nos anos 70 .

Os "anos de chumbo", desta vez no Brasil, são tema, ainda, do artigo A MULHER NOS ANOS 60: FRÁGIL OU SUBVERSIVA?, de Ândrea Quilian de Vargas, Ana Paula Fogaça Benchimol e Rosani Umbach, que investigam a construção da personagem Lena, protagonista de Tropical sol da liberdade, e sua relação com o contexto da Ditadura Civil-Militar de 1964. Para as autoras, "conhecer o romance de Ana Maria Machado, mergulhar na história de Lena, leva-nos a enxergar os "anos de chumbo" sob outro viés", o da subjetividade e do vigor linguístico de uma mulher às voltas com a escrita.

\section{LA EXCLUSIÓN SOCIAL DEL HOMBRE RURAL DURANTE LA}


POSTGUERRA CIVIL ESPAÑOLA, A TRAVÉS DE LA NOVELA LAS RATAS DEL ESCRITOR MIGUEL DELIBES é o artigo em Espanhol de Gracineia dos Santos Araújo, que trata da miséria do homem do campo na Espanha. A articulista constata que "Las circunstancias en las que viven los personajes de Las Ratas son fruto de un proceso histórico desolador, de una guerra que sembró el sufrimiento, la miseria y el hambre en todo el país, además de solidificar un sistema totalitario, católico y retrógrado."

Agradecemos aos autores que disponibilizaram seus textos e, assim, contribuem para a discussão em torno de tópicos como a violência, suas raízes, seus desdobramentos e, principalmente, suas formas de expressão nos textos literários estudados.

João Luis Pereira Ourique Rosani Úrsula Ketzer Umbach (Orgs.) 